\title{
Rescued satellite to get more managers
}

[WASHINGTON] Officials in charge of the newly recovered Solar and Heliospheric Observatory (SOHO) satellite are proposing that an extra layer of US-European management be added to guard against mishaps of the kind that nearly led to the satellite's loss last summer.

The proposal has been worked out by space science managers at the European Space Agency (ESA) and NASA's Goddard Space Flight Center. It would reinstate a SOHO programme office at Goddard that was due to be scrapped this autumn as the mission moved into a leaner, extended phase beyond its original two-year lifetime.

Management of the $\$ 1$ billion satellite was to have merged with that of other projects in the International Solar-Terrestrial Physics (ISTP) programme to save money. The proposed reinstated SOHO office would have minimal staff: a NASA programme manager and an ESA deputy, who would ensure that ground procedures receive closer scrutiny - particularly when procedures are changed.

Although Goddard handles ground operations for SOHO, ESA has final responsibility for the spacecraft's safety. The European deputy would therefore assume command in the event that SOHO's health was in jeopardy.

The proposal was presented this week to a NASA-ESA review board set up to decide whether SOHO is ready to resume normal scientific operation. The staffing plan will have to be approved by both space agencies.

A NASA-ESA investigation board concluded last August that a string of procedural and management errors led to the June mishap, during which the satellite's solar panels turned away from the Sun and drained nearly all the power from the batteries.

Among the problems identified by the board were inadequate review of changes to spacecraft command procedures, and an overloaded ground crew that was working too fast with too few people. The board called on the agencies to review staffing levels, and to add staff as required.

SOHO was brought back to life after heroic efforts by ESA and NASA teams working with engineers from satellite manufacturer Matra Marconi Space (see Nature 394, $5 \& 395,313 ; 1998)$. All 12 of the satellite's scientific instruments have now been restored to full health, although one coronagraph, for an instrument that tracks eruptions from the Sun, is still being tested.

John Credland, head of ESA's scientific projects department, says that his agency has spent several million dollars on the recovery and that, despite the near-miraculous comeback, neither ESA nor NASA want to have to repeat the experience. "If we just let things

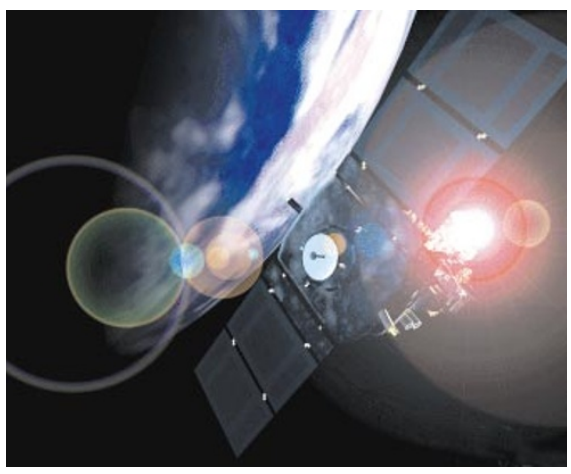

SOHO comeback: satellite is back in operation after it narrowly missed being lost in space.

revert to how they were before, we would not be responsible," he says.

But Credland says the incident should not be taken as an indictment of NASA's muchtouted "faster, better, cheaper" approach. Mario Acuña, the ISTP project scientist at Goddard, says it is not even clear that extra staff would help, rather than improved train- ing for contract workers at ground control. Both men say that cuts to mission operations are desirable and practical.

Yet the satellite's brush with disaster may serve as a warning that there are limits to the extent to which missions can be squeezed. NASA and Lockheed-Martin, the agency's new contractor for spacecraft ground operations across the board, are dedicated to cutting ground crews as much as possible to reduce the cost of space science missions.

According to Credland, the SOHO team started with 24 people, was planned to shrink to around 16, and is now likely to end up somewhere in between. The staff for the overall ISTP started at 200, but was planned to drop to 65 or 70 during the extended mission funded by NASA to continue observations during the forthcoming solar maximum. Acuña admits that the target staffing level is probably too low.

He says this week's readiness review is something of a formality, as $\mathrm{SOHO}$ is already back to full operation.

\section{Uruguay responds to scientists' protest}

[LONDON] Reacting to pressure from the scientific community, the government of Uruguay has promised to set up a fund to support basic research, with an initial budget of US\$1 million. It has also agreed to provide support for the only non-university research institute in the country, the Instituto Clemente Estable in Montevideo.

Both moves follow a protest letter sent by scientists in October to the country's president, Julio Maria Sanguinetti, complaining that the government's apparent lack of interest in supporting research was threatening to lead to the collapse of the science base.

Scientists argue that, since the restoration of democracy in Uruguay in 1985 , the country has managed to develop relatively strong activity in science and technology, despite the small size of the scientific community (Uruguay spent only 0.15 per cent of its gross national product on research and development in 1995, compared to 0.9 per cent in Brazil).

But many fear that this achievement is now at risk as the government focuses on other funding priorities. They point out that the government has failed to produce a promised five-year plan for science and technology, even though its term of office only has one more year to run.

The recent protest was triggered by difficulties at the Instituto Clemente Estable, founded by a former pupil of the Spanish neuroanatomist Santiago Ramon y Cajal. The private institute, one of the leading biological research labs in South America, had been threatened with closure as a result of a decision by the Congress to block its public funding.

In their letter to Sanguinetti, seeking support for the institute, the scientists also pointed out that salaries for researchers in Uruguay are considerably lower than in neighbouring countries, such as Brazil and Argentina. Andres Lalane, the president of the science council CONYCYT, says poor living and working conditions are driving scientists abroad or into other careers.

It is partly to address this situation that the government has now agreed to set up a National Research Fund. This will be run by the president of the University of the Republic, the president of CONYCYT, and the Ministry of Education and Culture.

The future of CONYCYT itself, however, remains uncertain, despite demands from the scientists that its role should be more clearly defined. CONYCYT is the main agency for promoting science in Uruguay.

Since its creation 30 years ago, the organization has operated largely independently of the government, bringing together researchers from the public and private sectors. There are now fears that the government plans to reduce its autonomy and the transparency with which it operates.

Despite such concerns, Uruguayan scientists say they are optimistic that the new initiatives are hopeful signs that a more productive dialogue may be developing with the government. Andrea Kauffmann-Zeh 